\title{
Paulo Freire, Myles Horton e Nicolaj F. S. Grundtvig: educadores dos oprimidos
}

\author{
Paulo Freire, Myles Horton and Nicolaj F. S. Grundtvig: \\ educators of the oppressed
}

\section{Paulo Freire, Myles Horton y Nicolaj F. S. Grundtvig:} educadores de los oprimidos

\section{SERGIO HADDAD}

Universidade de Caxias do Sul, Caxias do Sul- RS, Brasil.

\begin{abstract}
RESUMO: Trata-se de um ensaio comparativo entre três educadores cristãos que viveram em períodos e locais diferentes, mas com o mesmo compromisso de emancipação de setores populares. Suas ideias e práticas provocaram reações dos setores dominantes que tentaram impedi-los de educar, mas elas se espalharam e acabaram por impulsionar novas práticas e reflexões no campo da educação popular de jovens e adultos.
\end{abstract}

Palavras-chave: Nikolaj Grundtvig. Paulo Freire. Myles Horton. Educação Popular.

\begin{abstract}
It is a comparative essay concerning three Christian educators who lived in different periods and places, but with the same commitment of emancipation in popular sectors. Their ideas and practices provoked reactions from dominant sectors, those that tried to prevent them from teaching, but they were spread, and ended up being the driving force behind new practices and reflections in the field of youth and adult popular education.

Keywords: Nikolaj Grundtvig. Paulo Freire. Myles Horton. Popular education.
\end{abstract}

\footnotetext{
É graduado em Economia e Pedagogia. Possui mestrado e doutorado em História e Sociologia da Educação pela Universidade de São Paulo. Foi professor visitante da Oxford University. Atualmente, é pesquisador da Ação Educativa e professor da Universidade de Caxias do Sul. E-mail:<sergiohaddad@terra.com.br>.
} 
RESUMEN: Se trata de un ensayo comparativo entre tres educadores cristianos que vivieron en distintas épocas y lugares, pero con el mismo compromiso por la emancipación de los sectores populares. Sus ideas y prácticas provocaron reacciones de los sectores dominantes que intentaron impedirles educar, pero se difundieron y terminaron impulsando nuevas prácticas y reflexiones en el campo de la educación popular para jóvenes y adultos.

Palabras clave: Nikolaj Grundtvig. Paulo Freire. Myles Horton. Educación Popular.

\section{Introdução}

$\mathrm{P}$ aulo Freire e Myles Horton estiveram juntos em uma conferência em Los Angeles, na Califórnia, em 1987, quando conversaram pela primeira vez, por iniciativa de Paulo, sobre a possibilidade de "falar um livro"1. O convite foi aceito e, em dezembro daquele ano, os dois se encontraram na Highlander Folk School, escola fundada por Myles em 1932, no Tennessee, para dar início ao diálogo que se transformaria no livro O caminho se faz caminhando: conversas sobre educação e mudança social (FREIRE; HORTON, 2011).

A história do brasileiro Paulo Freire (1921-1997) é bastante difundida no Brasil², a do americano Myles Horton (1905-1990) nem tanto, e a do dinamarquês Nicolaj Frederik Severin Gundtvig (1783-1872) é praticamente desconhecida ${ }^{3}$. Horton inicia a experiência da Highlander, depois de passar um período na Dinamarca, conhecendo o movimento das Folk High Schools ${ }^{4}$, escolas que nasceram no século XIX, sob a inspiração do pensamento de Grundtvig.

Freire, em suas obras e entrevistas, não menciona o dinamarquês, mas parece improvável que ele não tenha conhecido seu pensamento, dado o grande reconhecimento das suas ideias para a educação de adultos na Europa ${ }^{5}$ e, em particular, para a Escandinávia. Paulo viveu em Genebra por dez anos (1970-1980). Nesse período, fez inúmeras viagens internacionais ${ }^{6}$, participando de debates, estudos e conferências, quando teve, certamente, a oportunidade de conhecer e discutir suas ideias. Em um certo momento do diálogo transcrito no livro acima mencionado, Paulo comenta com Horton: "Eu li um texto seu, aquele que você leu em Copenhague...". A nota de rodapé que menciona o texto e o evento diz:

Horton, Myles. Influences on Highlander Research and Education Center. New Market, TN, USA. Trabalho apresentado em uma oficina de Grundtvig, no Colégio Seminario Escandinavo, Dinamarca, 1983; publicado em Grundtvig's Ideas in North America - Influences and Parallels. Copenhague, Det Dansk Selskab, Instituto Dinmarquês, 1983 (FREIRE; HORTON, 2011:50, nota 2). 
Há, portanto, uma clara evidência sobre o conhecimento que Freire tinha a respeito de Grundtvig.

Os três educadores, apesar de viverem em séculos diferentes, apresentaram ideias e práticas semelhantes que os fizeram se aproximar de um campo específico da educação: o campo da educação popular de jovens e adultos. Para este trabalho, defino educação popular como uma prática social que se dedica à produção e circulação de conhecimentos, experiências e valores voltada à emancipação de jovens e adultos dos setores populares.

Paulo Freire nasceu em 1921, em Recife, cidade localizada no nordeste do Brasil, uma das regiões mais pobres do País. Sua família era de classe média, mas vivenciou a pobreza com a crise de 1929, quando foi obrigada a mudar para Jaboatão de Guararapes, cidade próxima de Recife, por problemas financeiros, agravados pela morte prematura do seu pai. Pela persistência da sua mãe, que zelava pela continuidade dos estudos do filho, conseguiu uma bolsa de estudos em uma das escolas mais tradicionais de Recife, o que lhe permitiu adquirir uma boa escolarização e desenvolver o gosto pelo ensino da língua portuguesa. Logo após se formar em Direito, abandonou a carreira de advogado precocemente e foi trabalhar com educação no Serviço Social da Indústria (Sesi) e ali ficou por mais de dez anos, realizando os primeiros experimentos educacionais com setores populares. Preocupado com o analfabetismo brasileiro, dedicou-se a desenvolver uma metodologia que permitisse, ao alfabetizar, que os alfabetizandos tomassem consciência dos seus problemas, de maneira a estimulá-los no envolvimento da solução. Após experimentar sua pedagogia com setores empobrecidos na cidade de Angicos, no Nordeste do País, em 1963, foi convidado a assumir a responsabilidade pela Campanha Nacional de Alfabetização, a ser lançada pelo governo progressista do presidente Jango Goulart. O Golpe Militar de 1964 interrompeu seu trabalho e o obrigou a exilar-se, depois de ficar preso. Sua pedagogia crítica ganhou o mundo no período em que esteve no exílio, principalmente a partir do lançamento do seu livro mais importante: Pedagogia do Oprimido, em 1970. Depois de correr o mundo, convidado para participar de uma série de eventos, de assessorar programas de educação e alfabetização no Chile e em países africanos que se libertaram do colonialismo português, retorna ao Brasil em 1980, como professor universitário, além de atuar em trabalhos de educação popular pelo País. Foi secretário de educação do município de São Paulo, por convite da prefeita Luiza Erundina do Partido dos Trabalhadores. Faleceu em 1997.

Myles Horton nasceu em 1905, no Tennessee, uma parte dos EUA cuja história está associada à monocultura em grandes propriedades, regime escravocrata e pobreza rural. Sua família, assim como a de Paulo, era de classe média, constituída por pais que trabalhavam como professores leigos e que acabaram por perder seus empregos pela exigência de titulação por parte do poder público. Como consequência, foram obrigados a viver em situação de pobreza, trabalhando em trabalhos diversos para sobreviver. Também como a de Paulo, sua família fez um esforço para propiciar a ele um curso superior. Depois de 
estudar Sociologia na Universidade de Chicago, Myles foi para a Dinamarca estudar as experiências de educação popular das Folk High Schools. Ao retornar para o Tennessee em 1932, fundou a escola Highlander Folk School, e aí ficou como diretor até 1972, quando se aposentou. Inicialmente, a Highlander realizava formação de lideranças rurais e operárias e atuava para a preservação dos valores indígenas das populações que ali viviam. Com a industrialização da região e a exploração do carvão, a escola voltou-se para a defesa dos direitos dos trabalhadores e ao apoio do trabalho sindical e às greves da região. $\mathrm{Na}$ década de 40, a escola passou a ser residencial, nos moldes das escolas dinamarquesas, e ofereceu formação de lideranças para movimentos sociais do Sul dos EUA. Nos inícios de 1950, apoiou o movimento pelos direitos civis, envolvendo-se com a questão da segregação racial e com o enfrentamento da supremacia branca. Um dos programas de maior repercussão desta escola popular foram as Escolas de Cidadania que se dedicavam a alfabetizar a comunidade negra para obter o direito de votar e fortalecer o seu poder político, à semelhança do que anos mais tarde Freire faria no Nordeste brasileiro. Muitas lideranças do movimento negro passaram pela Highlander, como a ativista Rosa Parks, que iniciou o boicote à cessão de lugares nos ônibus para brancos e Martin Luther King Jr. Horton faleceu em 1990.

Grundtvig nasceu em 1783, no seio de uma família sacerdotal, em uma aldeia ao sul da Zelândia, a maior ilha da Dinamarca. Seu pai era pastor, sua mãe cuidava da casa e dos filhos. Grundtvig era o menor de quatro irmãos e todos seguiram, como ele, a vida sacerdotal. Viviam uma vida simples, sem luxo. Assim como Paulo e Horton, aprendeu a ler muito cedo, o que o ajudou em sua formação nos anos seguintes, quando, em 1792, com nove anos de idade, foi enviado para outra cidade aos cuidados de um preceptor que forneceu-lhe educação de forma privada por seis anos. Mudou-se para Aarhus, em 1798, para fazer o secundário e para Copenhagen, em 1800, para estudar teologia. Em sua vida enfrentou conflitos no campo sacerdotal, com proibições e processos que o impediram de realizar o seu trabalho como pastor por sua postura crítica à tradição eclesiástica da sua igreja.

Grundtvig se sentiu desconfortável com sua vida escolar, tanto em Aarhus, como em Copenhagen, por seu academicismo e desprezo pela história, tradições e pela língua da Dinamarca. Por isso, dedicou-se a resgatar mitos e lendas tradicionais dinamarquesas. Com essa motivação, recebeu uma bolsa para ir à Inglaterra, país ao qual regressou por três vezes, entre 1829 e 1831, quando tomou contato e se encantou com o regime parlamentarista e o ambiente intelectual dos colleges das universidades inglesas. Depois desse período, participou ativamente do processo de transição da monarquia absoluta para parlamentarista com a Revolução Democrática de 1849. É neste contexto que suas ideias educacionais surgem, com críticas à escola tradicional, ministrada em latim, voltada a uma parcela reduzida da população. Grundtvig enveredou pela vida pública, tornando-se membro do parlamento. Aí passou a preocupar-se formalmente com a educação da 
população. A primeira Folk High School privada foi estabelecida no sul da Dinamarca, em 1844, em Rodding. Grundtvig não se empenhou pessoalmente em construir um modelo de escola baseada em suas ideias, mas Christen Kold, seu discípulo, implementou uma escola em Ryslinge, logo depois uma outra em Dalum, que foram as primeiras de uma sequência de novas experiências. O movimento das Folk High Schools se expandiu pela Dinamarca e pelos demais países da Escandinávia e parte do continente europeu. As primeiras escolas foram inauguradas na Noruega em 1864, na Suécia em 1868 e na Finlândia em 1889. Grundtvig foi pastor, salmista, historiador, renovador pedagógico e homem político e é considerado, junto com Hans Christian Andersen e Soren Kierkegaard, expoentes da chamada idade de ouro da Dinamarca. Faleceu em 1872 (DAM, 1983).

Apesar das distâncias históricas, geográficas e socioculturais que os distinguem, muitas são as semelhanças entre os três educadores quanto à trajetória pessoal e o pensamento pedagógico. Trato aqui de anotar algumas delas.

\section{A formação cristã}

Os três educadores foram criados dentro do cristianismo e seguiram suas vidas com os valores proclamados por ele, com uma doutrina que aproximava a fé com a realidade vivida pelas populações com as quais trabalhavam. Freire seguiu a religião católica da mãe (seu pai era espírita) e conviveu nos anos 1960 com a Ação Católica. Nunca foi uma pessoa de envolvimento com os ritos da igreja. “... não sou um homem religioso... Eu diria que sou um homem de fé" (FREIRE; HORTON, 2011:228). Nos anos setenta trabalhou no Conselho Mundial de Igrejas (CMI), entidade ecumênica cristã, constituída majoritariamente por igrejas, movimentos e entidades do protestantismo tradicional. Foi ali, em 1971, que escreveu seu texto mais incisivo sobre o papel educativo das igrejas na América Latina. Nele, à semelhança do que proclamou para a educação em Pedagogia do Oprimido, afirmou não haver neutralidade das igrejas diante da história, pois não são entidades abstratas, mas sim constituídas por homens e mulheres condicionados por realidades concretas (FREIRE, 1982): “Ao insistirem na inviável neutralidade da Igreja em face da história, em face das atividades políticas, não fazem outra coisa senão exercer uma atividade política, em favor, porém, das classes dominantes e contra as classes dominadas" (FREIRE, 1982:105).

Identificando-se com a Teologia da Libertação, afirmou a importância do papel da Igreja no trabalho de formação política e na ampliação da tomada de consciência dos setores oprimidos por meio da ação pastoral para que tivessem em suas mãos a responsabilidade por construir o seu destino.

Myles frequentou o seminário Union, no final da década de 20, e foi influenciado pelo pastor Reinhold Nieburhr, socialista e crítico social cristão (FREIRE; HORTON, 2011:23). 
Perguntado no diálogo com Freire sobre as razões que o colocaram em suas lutas, Myles respondeu que entre as muitas, uma seria o interesse dos seus pais pela educação e por crenças religiosas não opressoras (FREIRE; HORTON, 2011:213)

Grundtvig teve uma vida intensa e inquieta como pensador e pastor. Sempre lutando por suas ideias, viveu crises depressivas e conflitos com a hierarquia da Igreja Luterana Dinamarquesa, sofrendo momentos de censura e impedimento do exercício sacerdotal. Em um momento da sua vida foi designado pastor na Igreja de Salvador em Copenhagen e isto lhe permitiu voltar a ter contato com fiéis, atualizando suas concepções cristãs, depois de um período de recolhimento intelectual, trabalhando em traduções e textos de diversas naturezas, além da editoria de uma revista. Para ele, seria na comunidade eclesial, no batismo e na comunhão que Cristo brinda a comunidade com sua palavra viva. A comunidade é o que sempre existiu, antes inclusive da Bíblia ser escrita, dizia. Ele via a fé cristã como herança da comunidade religiosa através da sua história, portanto, da vida das pessoas (DAM, 1983:25-26).

Consequência ou não dos valores cristãos cultivados no âmbito familiar, todos tiveram uma infância acolhedora por parte dos pais, o que deu segurança para enfrentar os momentos mais difíceis de sobrevivência por suas famílias.

\section{A escolarização dos educadores e seus desconfortos}

A crença na educação, outra característica das suas famílias, produziu a alfabetização precoce realizada pelos pais e acabou por despertar em cada um deles o desejo pela leitura.

Grundtvig foi alfabetizado com quatro anos e passou a ler tudo o que foi possível em casa, mesmo não entendendo grande parte dos conteúdos daquilo que lia. Quando foi enviado ao preceptor, aprendeu latim, e seguiu com interesse nas leituras que chegavam sobre os fatos em torno da Revolução Francesa. Na sequência da sua formação, teve contato com uma vasta quantidade de livros, inclusive revistas políticas, que chegavam para o seu professor por meio de um clube de leitura. Ganhava Grundtvig consciência sobre o que vinha ocorrendo naquele momento histórico por meio da leitura.

Horton também começou a ler muito cedo, leu muito e de forma indiferenciada na infância e adolescência. Lia o que caia na sua mão, inclusive a Bíblia, que teve oportunidade de ler por duas vezes. Paulo, por outro lado, aprendeu a ler e escrever cedo com seus pais, escrevendo com um graveto no chão do quintal da sua casa em Recife, mas diferentemente de Horton e Grundtvig, não foi um leitor compulsivo na infância, apenas mais tarde, na juventude. 
Os três, no entanto, mesmo com comportamentos diferenciados durante os primeiros anos das suas vidas, só adquiriram prazer pela leitura quanto ela foi percebida como algo que vinculava o texto com os problemas cotidianos.

Segundo Horton,

Foi nesta fase (a juventude) que a leitura assumiu um significado completamente diferente para mim, porque eu estava lidando com os problemas reais da vida. Quando lia, eu recebia informações daquela leitura. Eu extraia ideias da leitura, ficava mais corajoso com ela, especialmente com a poesia, e a leitura assumiu um novo sentido (FREIRE; HORTON, 2011:58).

Similarmente, Freire afirmou:

Descobri que ler tinha que ser um ato de amor... Eu tinha uma conexão quase física com o texto. Foi essa experiência que começou a me ensinar como a leitura também é um ato de beleza porque tem que ver com o leitor reescrevendo o texto. É um evento estético. Eu devia ter uns 19 anos. Lembro sempre que foi uma sensação enorme de felicidade. Por causa disso, eu disse ao Myles que para mim não faz diferença se estou lendo poesia ou se estou lendo Marx. Tento obter a beleza no próprio ato de ler. Isso é ao meu ver uma coisa que muitas vezes os professores não tentam fazer (FREIRE; HORTON, 2011:55).

O desconforto expresso por Paulo sobre o papel dos professores no ensino da leitura reflete o mesmo sentimento de Myles:

Eu me lembro que, quando estava na escola secundária, a tristeza que me dava ver meus colegas não gostarem de ler poemas, contos ou literatura. Eu adorava ler, e eles detestavam. Eu sentia que eram os professores que faziam aquilo com eles, e isso me dava muito ressentimento (FREIRE; HORTON, 2011:55).

O mesmo ocorreu com Grundtvig, quando, depois dos seis anos vividos na casa do preceptor, cursou o ensino secundário em Aarhus e posteriormente a universidade em Copenhagen, e o seu sentimento foi de total desencanto e desinteresse pelos conteúdos e pelo distanciamento que as escolas mantinham com a realidade. Isso provocou nele forte crítica ao ensino tradicional, posteriormente incorporado aos seus trabalhos sobre educação e em suas práticas pedagógicas. "A fundamentação de sua rebeldia posterior contra o que ele viria a chamar por 'Escola da Morte' (quer dizer um ensino distante da vida e do espírito popular tal qual se praticava naqueles tempos), foi lançada nessa época" (DAM, 1983:13).

\section{A natureza política dos trabalhos dos educadores}

O gosto pela leitura, na medida que foi inspiradora para a compreensão da vida e dos projetos futuros, além de conter um componente estético, como salientou Paulo, foi 
algo comum na história dos três educadores. Mas as leituras eram também importantes para alimentar os objetivos políticos das práticas pedagógicas. E, nesse aspecto, algo particular ocorreu com cada um deles.

No diálogo com Freire, Horton valorizou a prática como sendo a inspiração primeira dos seus projetos políticos. Tinha como orientação começar a fazer as coisas e deixar que elas guiassem, por meio do trabalho coletivo, aquilo que poderia ocorrer no futuro. Esta foi a lógica de funcionamento da Highlander:

Estar nos lugares onde as coisas acontecem para saber o que fazer, encontrar os sinais de esperança para mudar a sociedade: o que nos resta é trabalhar com as sobras, trabalhar com pequenos focos de esperança e de espírito aventureiro onde quer que nos encontremos (...) só sabendo o que estava ocorrendo, nós éramos capazes de pressentir os locais onde havia potencial para uma mudança social radical" (FREIRE; HORTON, 2011:108).

As Escolas de Cidadania nasceram de uma demanda ao Highlander que foi feita por Esau Jenkins e Septima Clark, ambos de Johns Island, Carolina do Sul. Pediram auxílio para alfabetizar pessoas que queriam registrar-se como eleitores, já que não sabiam o suficiente para enfrentar os exames controlados pela má vontade dos funcionários brancos. Horton muda-se para o local para acompanhar a demanda, pois era assim que trabalhava a Highlander, partiam do conhecimento local sobre os problemas a serem enfrentados. Lá percebeu que várias tentativas de alfabetização haviam sido feitas sem sucesso, e que os sistemas tradicionais não funcionavam. Decidiram então convidar uma jovem negra, que já conheciam da Highlader, sobrinha de Septima, para começar um trabalho na ilha, sem nunca ter tido alguma experiência de alfabetização. Ela havia estudado até o secundário e estava ocupada em dirigir um salão de cabelereiros para negras, que era ao mesmo tempo um centro cultural da comunidade. Enfim, tinha uma forte identidade com a comunidade negra e se relacionava com ela de maneira horizontal.

Berenice tomou para si o desafio e passou a fazer seu trabalho por meio de ações práticas como escrever o nome, preencher boletos, e acabou utilizando a Declaração dos Direitos Humanos e a declaração de princípios da Highlander como material pedagógico. Foi uma experiência intuitiva que obteve sucesso, pois $80 \%$ dos alunos passaram no exame e puderam fazer o registro para votar. Logo outras pessoas procuraram Berenice para abrir novas turmas. Ela passou a formar educadores que se multiplicaram em novas escolas e expandiu o que acabou sendo chamada por Escola da Cidadania, começando pelas localidades mais próximas e logo se espalhando por várias partes do país. O programa começou em janeiro de 1957 e em 1961 já haviam capacitado mais de 400 professores, atingindo mais de quatro mil alunos (FREIRE; HORTON, 2011:92). A Highlander financiava a capacitação e a comunidade se encarregava de buscar local e professores, todos voluntários e negros. Depois deste sucesso, por solicitação do pastor Martin Luther King, o programa passou para as mãos da Conferência de Liderança Cristã do Sul, e Septima, 
junto com outras pessoas, foi ajudar na expansão do programa. O movimento de direitos civis já estava iniciando e as Escolas de Cidadania ocuparam um espaço central, com aulas noturnas de alfabetização e com resultados da ordem de 70 a $80 \%$ de sucesso no registro de eleitores. Cada escola era um projeto comunitário, transformava a vida das pessoas, que seguiam posteriormente para programas de pós-alfabetização, com objetivos definidos por essas comunidades.

Para Freire, a preocupação em Angicos foi a de buscar, por meio do seu método, a motivação para que as pessoas se alfabetizassem a partir de temas existenciais que se transformavam em palavras geradoras e seriam posteriormente decodificadas em sílabas, que serviriam para a construção de novas palavras. Assim se daria o processo de aquisição da leitura e da escrita, tendo por base os problemas que se apresentavam na vida dos grupos que se dispunham a estudar. Discutir seus problemas, buscar as razões para a sua existência nas condições em que estavam, encontrar soluções para elas eram a motivação política do processo de leitura e escrita. Paulo chamava de "círculos de cultura" o espaço no qual se realizam os processos de leitura do mundo e leitura da palavra. Era o sentido político do trabalho de alfabetização.

Segundo Korsgaard (2019), as ideias de Grundtvig sobre a Folk High School estavam ligadas à sua avaliação sobre os impactos da Revolução Francesa de 1789, que, ao mesmo tempo em que abriu uma nova época para a história, trouxe caos social e terror. A resposta para sua aspiração de transformação com paz social seria uma nova instituição que promovesse a conscientização e a edificação social, pessoal e política e que tivesse como princípio central a interação entre o trabalho manual e o espírito, entre professores e alunos, entre o passado e o presente, entre liberdade e ordem (KORSGAARD, 2019: 16). A escola deveria ter uma profunda união entre história e poesia, poesia aqui entendida como poesis, derivada da palavra grega cujo significado é criação. Para Grundtvig, seria a criação individual e societária. Portanto, uma escola histórica-poética para garantir uma transição não violenta para uma nova forma de sociedade centrada na identidade cultural popular e que implicaria, naquele momento, uma nova percepção da questão da nação, da questão social, com a promoção do povo, uma escola não confessional, baseada na sua língua materna, o dinamarquês (KORSGAARD, 2019:17).

Há que se lembrar que no início do século XIX a sociedade dinamarquesa tinha por base vários estratos: a nobreza, o clero, a burguesia e os camponeses. Grundtvig estava preocupado com a promoção dos camponeses, que tinham direitos desiguais frente aos demais.

Para promover este processo, uma nova forma de escola deveria ser criada, uma faculdade para o povo, que ajudaria a desenvolver uma forma de sociedade "do povo" baseada na ideia de igualdade entre as pessoas. $\mathrm{O}$ antigo sistema patrimonial, fundado na noção de desigualdade, deveria ser quebrado pela exigência de igualdade (KORSGAARD, 2019:20). 
Grundtvig, muito insatisfeito com as escolas, afirmava que os conteúdos memorativos e os métodos estagnados tinham um efeito de morte para os estudantes. Ele a chamava de escola da morte ou escola da escuridão, uma escola que só atendia aos interesses de uma parcela da sociedade (KNUDSEN, 1976). Pregava, portanto, uma escola popular, inspirado na experiência inglesa das tutorias entre os professores e alunos que se davam nas universidades, em contraste com a rigidez das relações desenvolvidas na Dinamarca. Em seus escritos, passou a valorizar as tradições gregas e nórdicas contrárias à racionalidade legalista romana e à língua latina vigentes, e acentuou a importância da comunicação oral ou da "palavra viva" (living word), da interação, da liberdade, da vida (KNUDSEN, 1976).

\section{A perseguição aos educadores por suas ideias}

Os responsáveis pelo Golpe Militar de 1964 no Brasil intuíram que o Programa Nacional de Alfabetização, encabeçado por Paulo Freire, ganhando dimensão nacional, poderia desestabilizar poderes constituídos ao capacitar, no curto prazo, grande quantidade de pessoas para o voto, então vedado aos analfabetos. Além disso, dadas as características do método, que permitia que setores populares influíssem de maneira mais consciente em seus destinos, não era de interesse dos setores conservadores que estavam do poder. Seria necessário, portanto, banir e deslegitimar a ação e seu autor.

Em 18 de outubro de 1964, alguns dias depois de Paulo Freire ter partido para o exílio, o tenente-coronel Hélio Ibiapina Lima divulgou o texto final do inquérito que comandou contra o educador, acusando Paulo Freire de ser "um dos maiores responsáveis pela subversão imediata dos menos favorecidos. [...] Sua atuação no campo da alfabetização de adultos nada mais é que uma extraordinária tarefa marxista de politização das mesmas", escreveu. Para Ibiapina Lima, Freire não teria criado método algum e sua fama viria da propaganda feita pelos agentes do Partido Comunista da União Soviética. "É um cripto-comunista encapuçado sob a forma de alfabetizador", informava o relatório (HADDAD, 2019).

Na apresentação do livro Educação como Prática da Liberdade, Francisco Weffort (1967:11) assim analisou os fatos ocorridos no Brasil:

\footnotetext{
Nestes últimos anos, o fantasma do comunismo, que as classes dominantes agitam contra qualquer governo democrático da América Latina, teria alcançado feições reais aos olhos dos reacionários na presença política das classes populares... Todos sabiam da formação católica do seu inspirador e do seu objetivo básico: efetivar uma aspiração nacional apregoada, desde 1920, por todos os grupos políticos, a alfabetização do povo brasileiro e a ampliação democrática da participação popular... Preferiram acusar Paulo Freire por ideias que não professa a atacar esse movimento de democratização cultural, pois percebiam nele o gérmen da derrota.
} 
E acrescentaria: "Se a tomada de consciência abre caminho à expressão das insatisfações sociais, é porque estas são componentes reais de uma situação de opressão" (WEFFORT, 1967).

Horton, da mesma forma, em 1954, foi investigado por supostas conexões comunistas, pelo senador James Eastland, um rico fazendeiro de Mississipi e defensor da supremacia branca. Em outro famoso incidente, o governador segregacionista da Georgia, Marvin Friffin, enviou espiões para a celebração de 25 anos da Highlander, onde Martin Luter King era o orador principal. Foram tiradas fotos de King, Horton e outros que, preparadas no formato de cartazes, foram coladas em todo o Sul com a legenda: "King em uma escola de treinamento comunista". Em 1959 a Highlander Folk School foi invadida por agentes do Tennessee e seus bens móveis e imóveis foram confiscados. Depois do ocorrido, Horton mudou o nome da escola para Highlander Research and Education Center (Centro de Pesquisa e Educação Highlander) e transferiu-a para Knoxville-e, mais tarde, para New Marked, onde está até hoje" (FREIRE; HORTON, 2011:30)

\section{O impacto dos trabalhos dos educadores}

Paulo Freire recebeu mais de 50 títulos doutor honoris causa por diversas universidades no Brasil e no exterior. São inúmeras escolas, grêmios estudantis, teatros, auditórios cátedras, ruas, avenidas com o seu nome. Muitos prêmios e condecorações foram criados em sua homenagem. Suas obras foram traduzidas para diversas línguas e espalhadas pelo mundo. Pedagogia do Oprimido foi publicado em mais de vinte línguas. Há traduções das suas obras para valenciano, coreano, japonês, hindi, iídiche, hebraico, sueco, holandês, indonésio, dinamarquês, ucraniano, finlandês, paquistanês e basco. Vários centros de pesquisa e organizações não governamentais no mundo levam o nome de Paulo Freire. Em junho de 2016, uma pesquisa revelou que Pedagogia do Oprimido era a terceira obra mais citada em trabalhos da área de humanas, segundo um levantamento feito no Google Scholar. Este reconhecimento vem se traduzindo em inúmeras experiências de trabalho educacionais (HADDAD, 2019).

As Folk High School (FHS) tiveram um impacto crescente não só pela sua proposta, mas pela multiplicação das suas unidades. Entre 1864 e 1872, 60 FHS foram estabelecidas voltadas para educação dos camponeses. O slogan "de camponês para povo" foi frequentemente usado até meados do século XX para destacar o objetivo da educação dos jovens homens e mulheres nas Escolas do Povo. A grande importância de Grundtvig para a formação do estado-nação dinamarquês moderno está ligada à sua luta incessante para emancipar os camponeses cultural e socialmente. Para ele, havia uma profunda conexão entre a questão da nacionalidade e o status da classe camponesa no sentido de que o desenvolvimento da consciência nacional exigia maior igualdade social e cultural. 
A importância do trabalho da Highlander para a sociedade norteamericana, particularmente para os afrodescendentes, baseada na experiência dinamarquesa, foi reconhecida pelo presidente Obama em homenagem a cinco líderes nórdicos que participaram de um jantar de Estado, no dia 13 de maio de 2016 na Casa Branca.

Muitos de nossos amigos nórdicos conhecem o grande pastor e filósofo dinamarquês Grundtvig que, entre outras causas, defendeu a ideia da Escola Popular (Folk High School), que prepara uma pessoa para a cidadania ativa, que melhora uma sociedade.

Com o tempo, o Movimento das Escolas Populares se espalhou, inclusive aqui nos Estados Unidos. Uma dessas escolas ficava no estado do Tennessee. Foi chamada de Highlander Folk School. Em destaque, especialmente durante os anos 50, uma nova geração de americanos se reuniu para compartilhar suas ideias e estratégias para o avanço dos direitos civis, para o avanço da igualdade, para o avanço da justiça. Conhecemos os nomes de alguns dos que participaram da escola Highlander. Ralph Abernathy. John Lewis. Dr. Martin Luther King, Jr.

Todos eles foram influenciados em parte pela Highlander e pelos ensinamentos do grande filósofo nórdico, e acabaram tendo impacto no Movimento dos Direitos Civis e, em última instância, em fazer da América um lugar melhor. Não teríamos estado aqui se não fosse aquela pedra que foi jogada no lago e criou ondas de esperança que acabaram se espalhando pelo oceano até os Estados Unidos da América. Talvez eu não estivesse aqui se não fosse pelo esforço de pessoas como Ella Baker e os outros que participaram da Highlander Folk School.

\section{Um mundo melhor}

Três educadores cristãos, comprometidos com a emancipação de setores populares, formularam concepções educativas e práticas em tempos históricos diversos. Como consequência, mexeram com interesses dos setores dominantes de seus países. Foram perseguidos e tentaram impedi-los de educar, no entanto, suas ideias se espalharam e influenciaram novos educadores e educadoras que vêm ajudando a construir, por meio de uma educação popular, um mundo melhor, com menos desigualdade e mais justiça social.

Recebido em 19/07/2020. Aprovado em 05/08/2020.

\section{Notas}

1 Paulo Freire produziu um conjunto de livros a partir de diálogos realizados com outros educadores como, por exemplo, Frei Betto, Antonio Faundes, Mário Sérgio Guimarães, Moacir Gadotti, Adriano Nogueira, Donaldo Macedo, Ira Shor, Henry Giroux. 
2 Ver em particular: HADDAD, 2019; FREIRE, 2006; GADOTTI, 1996)

3 Na literatura brasileira encontramos uma única e breve referência ao autor e aos movimentos das escolas populares da Dinamarca, mencionados na monografia "Educação Supletiva-Educação de Adultos" de Paschoal Lemme, de 1938 (LEMME, 2004:51).

4 Folk pode ser traduzido para People em inglês, ou seja, povo em português. No entanto, no dinamarquês, refere-se ao conjunto de integrantes de um país de uma dada cultura e não, provavelmente, ao setor mais pobre da população. Ao mesmo tempo, High School, na tradução inglesa da palavra dinamarquesa hjoskole, não tem o sentido de ensino médio, mas de uma escola "superior" para jovens e adultos.

5 Esta relevância se constata, por exemplo, pelo nome dado ao Programa Grundtvig sobre Educação de Adultos da Comunidade Europeia que distribuiu 358 milhões de euros para projetos multilaterais entre 2007 e 2013. Foi sucedido pelo Programa Erasmus 2014-2020.

6 Conforme ANDREOLA; RIBEIRO, 2005, Paulo Freire fez mais de 150 viagens internacionais nos dez anos que permaneceu em Genebra trabalhando no Conselho Mundial de Igrejas.

7 Traduzido pelo autor do Washington Post, 14 de maio de 2016.

\section{Referências}

ANDREOLA, Balduino Antonio.; RIBEIRO, Mario Bueno. Andarilho da Esperança: Paulo Freire no Conselho Mundial de Igrejas. São Paulo: Aste, 2005.

DAM, Poul. N.F.S. Grundtvig. Copenhague K: Ministério de Relaciones Exteriores de Dinamarca, 1983.

FREIRE, Ana Maria Araújo. Paulo Freire: uma história de vida. Indaiatuba: Villa das Letras, 2006.

FREIRE, Paulo, Ação cultural para a liberdade e outros escritos. Rio de Janeiro: Paz e Terra, 1982.

FREIRE, Paulo; HORTON, Myles. O caminho de faz caminhando: Conversar sobre educação e mudança social. $6^{\mathrm{a}}$ ed. Petrópolis: Vozes, 2011.

GADOTTI, Moacir. Paulo Freire: Uma biobibliografia. São Paulo: Cortez, Instituto Paulo Freire; Brasília: Unesco, 1996.

HADDAD, Sergio. O Educador: um perfil de Paulo Freire. São Paulo: Todavia, 2019.

KORSGAARD, Ove. A foray into Folk High School ideology. Denmark: Association of Folk High Schools in Denmark, 2019.

KNUDSEN, Johannes (ed.) N.F.S. Grundtvig: Selected Writings. Philadelphia: Fortress Press, 1976

LEMME, Paschoal. Memórias 5; estudos de educação e destaques da correspondência. Organizado por Jader de Medeiros Britto. Brasília: INEP, 2000.

WEFFORT, Francisco Correia. Educação e Política. IN: FREIRE, P. Educação como prática da liberdade. Rio de Janeiro: Paz e Terra, 1967. 